\title{
A importância de Hans Prinzhorn para a reforma psiquiátrica no Brasil
}

\author{
The importance of Hans Prinzhorn for psychiatric reform in Brazil
}

Fernando Ferreira Pinto de Freitas' ${ }^{\mathbf{1}}$, Paulo Duarte de Carvalho Amarante ${ }^{\mathbf{2}}$

DOI: 10.1590/0103-1104201811713

RESUMO A autonomia do campo artístico-cultural com relação ao campo psiquiátrico é uma tendência que vem sendo fortalecida na reforma psiquiátrica brasileira, tendo como precursores históricos Osório César e Nise da Silveira. Com a assistência sendo deslocada do hospital para o território, novas questões surgem. O artigo explora o papel pioneiro de Hans Prinzhorn para a abordagem das relações entre a arte e a loucura, apresentando os principais fundamentos da sua obra.

PALAVRAS-CHAVE Prinzhorn. Arte. Reforma psiquiátrica. Saúde mental.

ABSTRACT The autonomy of the artistic-cultural field with regard to the psychiatric field is a trend that has been strengthened in the Brazilian psychiatric reform, having as historical precursors Osório César and Nise da Silveira. With assistance moving from the hospital to the territory, new issues arise. The article explores the pioneering role of Hans Prinzhorn to address the relationship between art and madness, presenting the main fundamentals of his work.

KEYWORDS Prinzhorn. Art. Psychiatric reform. Mental health.

1 Fundação Oswaldo Cruz (Fiocruz), Escola Nacional de Saúde Pública Sergio Arouca (Ensp), Laboratório de Estudos e Pesquisas em Saúde Mental e Atenção Psicossocial (Laps) - Rio de Janeiro (RJ), Brasil. ffreitas@ensp.fiocruz.br

2 Fundação Oswaldo Cruz (Fiocruz), Escola Nacional de Saúde Pública (Ensp), Laboratório de Estudos e Pesquisas em Saúde Mental e Atenção Psicossocial (Laps) - Rio de Janeiro (RJ), Brasil.

pauloamarante@gmail.com 
Deve-se resolver definitivamente levar em consideração, uma vez por todas, o componente produtivo e tomar como critério para julgar uma obra o nível de como ela é colocada em forma ('Gestaltung') - aí incluindo-se o esquizofrênico.

(Hans Prinzhorn).

\section{Prinzhorn e a reforma psiquiátrica}

A arte dos usuários dos serviços psiquiátricos é foco de grande interesse no processo de reforma psiquiátrica brasileira. Há numerosos artigos e livros publicados, teses de pós-graduação se multiplicam.

Será que a reforma psiquiátrica está criando novas condições na relação entre a arte e os artistas-usuários?

Desde Pinel', é tradicional no 'campo psiquiátrico' que sejam disponibilizados aos pacientes meios artísticos, para que venham a ocupar o tempo ocioso, a fim de ficarem mais dóceis, senão para que estejam em atividades consideradas de 'arte-terapia'. É dentro deste contexto, historicamente condicionado para subordinar a arte aos imperativos da instituição psiquiátrica, que a reforma psiquiátrica brasileira vem demonstrando ser viável o reconhecimento do chamado 'campo artístico-cultural' com a sua própria racionalidade.

Entendendo que a reforma psiquiátrica seja, por natureza, um processo social complexo $^{2}$, transformações nas dimensões da epistemologia, da clínica, no campo jurídico e na dimensão 'cultural' são essenciais. A bem da verdade, é a dimensão 'cultural' o catalizador das outras três dimensões, não apenas porque assimila as conquistas das demais, mas sobretudo porque são as mudanças no modo como os sujeitos se posicionam no mundo, como o veem e como o entendem, que garantem e sustentam como o ‘sofrimento psíquico' será abordado em suas manifestações.
A hipótese trabalhada no artigo é de que, no processo de reforma psiquiátrica brasileira, vem se destacando a tendência ao reconhecimento da autonomia do campo 'artístico-cultural' com relação ao campo 'psiquiátrico'. Trata-se de uma demanda que cada vez mais ganha expressão no cenário público, formulada de distintas maneiras por 'usuários-artistas', 'famílias', 'profissionais de saúde mental' e movimentos sociais organizados, em busca de reconhecimento de suas produções artístico-culturais, o que desafia esquemas conceituais e operacionais tradicionais ${ }^{3}$.

É verdade que os psiquiatras historicamente têm estado interessados no que a arte dos chamados doentes mentais revela acerca do estado mental dos artistas. É muito comum o emprego de produções artísticas como demonstração de doença mental, o que é contestado historicamente pelo campo artístico, quando os artistas reivindicam encontrar nas produções dos doentes mentais - como os psicóticos, por exemplo - uma libertação dos padrões culturais convencionais e da própria ortodoxia estética. Tradicionalmente, tais obras são consideradas como arte dos pacientes de asilos. Como pensar e dar valor estético às produções que hoje são feitas fora dos asilos psiquiátricos? E produzidas por 'usuários' que não necessariamente têm o diagnóstico de psicose, mas de depressão, transtornos de ansiedade, Transtorno do Deficit de Atenção com Hiperatividade (TDAH) etc.??

A ideia do presente artigo é retomar a obra do psiquiatra alemão e crítico de arte Hans Prinzhorn (1886-1933) e se debruçar sobre o que se pode aprender com a sua perspectiva. Neste estudo, Prinzhorn ganha uma forte relevância, frente aos desafios desinstitucionalizantes que a reforma hoje enfrenta, com relação às experiências artísticas e culturais. Prinzhorn ainda é muito pouco conhecido entre os brasileiros, as referências à sua obra costumam aparecer marginalmente ${ }^{4-7}$. E isto contrasta com o destaque que costuma ser dado a Osório César e Nise da Silveira, não 
por acaso, pois é inegável o papel histórico destes dois psiquiatras brasileiros, que dedicaram suas vidas profissionais ao reconhecimento da importância das atividades artísticas e culturais como alternativas ao tratamento psiquiátrico dominante.

Um breve histórico: desde que Osório César foi designado estudante interno de psiquiatria do Hospital Juqueri, em 1923, ele passou a se interessar pela ideia de estudar a arte dos pacientes psiquiátricos, comparando-a com a arte dos chamados povos primitivos e a arte das crianças. As representações de arte desses doentes, diz Osório César8, são todas emocionais, pois elas são de caráter espontâneo e se dirigem para um fito único: a satisfação de uma necessidade instintiva. Elas representam descargas acumuladas de emoções, durante muito tempo no subconsciente adormecidas pela censura, em virtude de certos impulsos de ordem moral ${ }^{8}$. Por sua vez, Nise da Silveira, criadora do Museu de Imagens do Inconsciente no Centro Psiquiátrico Nacional, reconhece que os críticos de arte haviam sido sempre mais atentos ao fenômeno da produção artística dos esquizofrênicos do que os psiquiatras no mundo inteiro, e, em particular, entre os brasileiros, fazendo questão de destacar duas exceções: Prinzhorn e Jaspers. A respeito de Prinzhorn, objeto deste artigo, Nise fez a seguinte observação, que não pode deixar de ser citada:

H. Prinzhorn escreveu um livro verdadeiramente extraordinário, publicado em 1922: Bildnerei der Geisteskranken. Psiquiatra do hospital de Heildelberg, estudou as obras plásticas de esquizofrênicos, guiando-se unicamente pelo conceito de configuração ('Gestaltung') e mantendo-se independente da psiquiatria e da estética9(14-15).

Qual é a importância da obra de Prinzhorn para os tempos atuais? De imediato, o modo 'revolucionário' como ele, já na década de 1920, apresentou para o grande público o valor estético das obras produzidas por pacientes psiquiátricos. Suas inovações tiveram um forte impacto, não apenas no modo como a psiquiatria tradicionalmente se relacionava com a produção dos seus pacientes, mas também como a sociedade considerava o que as pessoas ditas insanas produziam. De forma muito particular, no modo como as inúmeras contribuições dos considerados loucos passaram a ser vistas como parte das inovações buscadas com afinco pela própria arte moderna. Por conseguinte, contextualizar a obra de Prinzhorn no processo de reforma psiquiátrica brasileira certamente dará uma importante referência para a criação das novas perspectivas que vêm sendo perseguidas; o que é objeto da primeira parte deste artigo. A segunda parte tem como escopo a teoria desenvolvida por Prinzhorn, de natureza eminentemente estética, que, embora dialogue com a ciência da psicologia do seu tempo, é rica de intuições que muito têm em comum com a crítica da arte do século XX.

\section{Contextualizando Prinzhorn em seu tempo e nos tempos atuais}

A relação entre a arte e a loucura começou a despertar o interesse da investigação científica entre o fim do século XIX e o começo do século $\mathrm{XX}^{10}$. Por um lado, as concepções do que é arte estavam experimentando rápidas e profundas mudanças, e expansão junto à opinião pública da época; por outro lado, a loucura estava aparecendo como objeto de investigação científica, graças a Kraepelin, Freud, Bleuler e Jung, por exemplo.

A formação de grandes coleções organizadas pelos próprios psiquiatras, de obras produzidas por seus pacientes, possibilitou estudos comparativos. Esse foi o caso de uma investigação da arte dos pacientes produzida em um pequeno hospital na Itália, em 1880, relatada por MacGregor ${ }^{10}$. No Asilo de San 
Benedetto, em Pesaro, que abrigava 388 pacientes, o Dr. L. Frigerio tomou a iniciativa de agrupar as centenas de imagens produzidas pelos pacientes para fazer estudos que visavam encontrar similaridades entre $o$ 'produto artístico' e a 'condição mental' dos pacientes, e, com isso, exemplificar as categorias de diagnóstico vigentes em sua época. Ainda na Itália, a coleção feita pelo psiquiatra e criminologista Cesare Lombroso (18351909) fez história. Em um dos capítulos do livro 'L'Uomo di genio' (O homem do gênio), Lombroso pretendeu demonstrar que as imagens concebidas pelos doentes mentais permitiriam identificar sintomas de patologia. Segundo o psiquiatra, que enfatizou conceitos tais como hereditariedade e degeneração física entre os doentes mentais, a investigação das imagens produzidas pelos pacientes psiquiátricos internados seria um bom método para o desenvolvimento de estratégias de diagnóstico. Pouco a pouco, a sua proposta conquistaria um interesse generalizado"1. Percebe-se claramente não haver, até então, qualquer interesse pela dimensão estética das obras. A ênfase estava totalmente voltada para a 'clínica': as obras realizadas em contexto psiquiátrico eram apenas um meio de diagnóstico, de aproximação à psicopatologia do paciente.

Um parêntese para falar de Freud e a psicanálise freudiana: tendo sido considerado o responsável pela descoberta do inconsciente, Freud via a arte como um importante meio para confirmar as suas teses sobre como o inconsciente funcionava. Pela perspectiva da arte, ao demonstrar ser falsa a soberania da consciência frente à força e aos conteúdos do inconsciente, a influência de Freud tornou-se inestimável. Dar voz ao inconsciente seria, para o campo artístico, criar condições para rupturas com os estreitos limites ditados pela consciência, abrindo as portas para a criatividade. Foi um marco para a modernidade, no romper do século XX (precisamente em 1900), a publicação de 'A interpretação dos sonhos', onde Freud desenvolve a sua noção de inconsciente ${ }^{\mathbf{1 2}}$. A partir dali, ficou impossível lidar com a visão da 'realidade' da mesma maneira de outrora. Com o 'inconsciente' freudiano, passa a ser um grande equívoco abordar a 'realidade' sem que os conteúdos 'manifesto', 'visível' e 'tangível' sejam integrados aos novos conteúdos 'inconscientes' - aqueles que não podem ser apreendidos de modo direto. Sob a perspectiva da arte, as imagens representadas na pintura, na escultura, no teatro e na música, por exemplo, devem ser interpretadas como as próprias imagens oníricas, o que permitirá à psicanálise segundo Freud buscar nas produções artísticas uma confirmação das teses que interpretam as produções oníricas criadas no 'divã'. Os dois ensaios de análise de obras de arte que Freud realizou, a saber, 'Uma recordação de infância de Leonardo da Vinci'13, e 'Moisés de Michelangelo'14, são abordagens do 'campo artístico' que reduzem a lógica estética dos seus criadores e da recepção dessas obras a um conjunto de teses 'psicanalíticas' que ele, Freud, havia elaborado. Freud não dissociava a noção de inconsciente de um estado patológico. Por conseguinte, a emersão dos conteúdos inconscientes, através da atividade onírica ou artística - não importa, porque são similares -, representa a via para o autoconhecimento e, por conseguinte, para a cura.

Foi com o movimento conhecido como Surrealismo que a aliança da psicanálise com a arte ganhou, certamente, a sua maior expressão. Desde as suas origens, o Surrealismo, tal como foi concebido por André Breton, esteve amplamente enraizado nos escritos de Freud. O conteúdo do primeiro manifesto do Surrealismo, de 1924, é inseparável do livro 'A interpretação dos sonhos' e de outros primeiros trabalhos de Freud. Da associação livre, como método para a abordagem do inconsciente, e do livre jogo dos movimentos do criador, como método da arte, materiais semelhantes foram produzidos. Por isso, Breton afirma: 
Eu acredito na futura resolução desses dois estados, o sonho e a realidade, que são aparentemente tão contraditórios, para um tipo de realidade absoluta, uma 'surrealidade', se alguém pode assim falar. É na busca dessa surrealidade que eu estou indo15(14).

Retomando a descrição que vinha sendo feita, da tendência a formar coleções com as obras produzidas pelos pacientes psiquiátricos, houve a histórica exposição realizada na passagem do século XIX para o século XX, no emblemático Bethlem Royal Hospital, em Londres. Ela foi promovida por Theophilus Bulkeley Hyslop, médico e diretor do local entre 1898 e 1910, que gostava de colecionar as obras produzidas pelos pacientes do asilo onde trabalhava. Hyslop, além do cargo em Bethlem, era um membro honorário do London Sketch Club e um ocasional expositor na Royal Academy. Pois bem, em 1900, ele realizou no Bethlem a primeira exposição pública de uma coleção de arte de pacientes psiquiátricos de que se tem conhecimento. $\mathrm{O}$ ineditismo dessa exposição teve importantes repercussões internacionais ${ }^{10}$. Um dos desdobramentos desse evento em Londres foi o Mad Museum, criado pelo psiquiatra Auguste-Armand Marie, que havia sido aluno de Charcot, enquanto diretor do gigantesco Asilo de Villejuif, nos arredores de Paris. A respeito, MacGregor diz o seguinte:

A coleção de Villejuif foi por muitos anos a base de todos os estudos na França sobre a arte dos insanos, assim como a principal fonte de informação e imagens para artistas e amantes da arte interessados em ver aí uma forma de arte desconhecida10(171).

Mas foi com um crítico de arte e homem de letras, Paul Meunier, conhecido pelo seu pseudônimo Marcel Réja, que, pela primeira vez, no começo do século XX, ganhou vulto a expressão artística propriamente dita das obras produzidas por pacientes psiquiátricos, isto é, foi reivindicada a autonomia do campo artístico com relação ao campo psiquiátrico. Como é dito por MacGregor:

['L'art chez les fous'] foi o primeiro livro completamente dedicado a um estudo da atividade espontânea de produção de imagens de pacientes considerados a partir do ponto de vista da crítica da arte10(172).

O estudo feito por Réja não apenas aprofundou a compreensão dos processos criativos dos 'insanos', mas também, e, sobretudo, em termos estéticos, ampliou as perspectivas em torno da arte convencionalmente reconhecida. Em 'L'Art chez les fous', Réja abordou diferentes modalidades de expressão artística: desenho, pintura, escultura, poesia, prosa, música e dança. Nesse livro, ele realizou estudos comparativos, sim; mas do ponto de vista estético, estabelecendo paralelismos entre a arte dos chamados 'doentes mentais', dos prisioneiros, dos chamados povos primitivos e pintores 'naïf', das crianças e dos visionários; o que ele almejava com isso era investigar a própria origem do 'impulso criativo'10. Réja pode ser considerado um dos precursores da própria modernidade na arte, que, de uma forma ou de outra buscou explorar as mesmas analogias. Como diz MacGregor: "Para a concepção de Réja do que é arte e a sua função, o seu conteúdo emocional é um elemento essencial” 10(172).

Chega-se finalmente a Prinzhorn. Ele ganhou seu lugar na história mundial graças à coleção de obras de arte que organizou na Clínica de Heidelberg (Alemanha), assim como com a produção de um livro sobre o tema. Seria Prinzhorn mais um a colecionar obras de pacientes psiquiátricos para fins de diagnóstico e para exibição de coisas bizarras? Absolutamente não. A coleção de Heidelberg havia sido iniciada na primeira década do século XX, sob a direção de Emil Kraepelin (1890 a 1903), constituindo um acervo para finalidades didáticas. Em 1919, Prinzhorn tornou-se assistente do Dr. Karl Wilmanns, na época, diretor da Clínica de Heidelberg, e dele 
recebeu a tarefa de alargar a coleção de arte, a fim de desenvolver um projeto de investigação científica para fins médicos. Em dois anos e meio, Prinzhorn constituiu uma coleção com cerca de 5 mil peças, obras de 'doentes' em sua maioria sem formação artística prévia, vindas de cerca de 450 casos, provenientes de vários países da Europa. Ele também apresentou o estudo desse acervo sob a forma de uma ambiciosa obra, 'Bildeneri der Geistestkranken'. Esse livro entrou na história como um ato inaugural. Pela primeira vez, segundo André Breton ${ }^{15}$, foi assegurada às obras produzidas nos asilos uma apresentação digna delas.

Felizmente para a história, Prinzhorn se distanciou da tarefa que lhe havia sido confiada. Ele questionou o valor 'sintomático' das características do material estudado, abandonando toda a classificação nosológica em proveito de uma ordem de apresentação segundo critérios estéticos - das formas menos elaboradas até aquelas cujas sofisticações poderiam ser comparadas às obras dos grandes mestres das artes plásticas. Ao invés de elaborar documentos brutos em material didático, ele os transformou em pinacoteca. Prinzhorn confrontou a produção dos pacientes psiquiátricos com as concepções artísticas da época, em particular, o movimento de vanguarda representado pelo expressionismo alemão.

Em 1921, o que estava exposto no Museu da Clínica de Heidelberg já era tema de debate público, mas não em termos de supostos avanços na psiquiatria, porém enquanto tendências que a arte vinha assumindo no começo do século XX. Jornalistas começavam a comentar o que viam em suas visitas ao museu, frequentemente com uma postura de estranheza, o que era de se esperar frente às novidades. Esse foi o caso de Fritz Stahl, citado por Marielène Weber, que, em seu artigo assinado em 30 de junho de 1921, entre outras coisas, diz:

Observemos de passagem que a semelhança de certas obras modernas com esses trabaIhos repousa sobre o fato de que os artistas colocam deliberadamente a razão fora de circuito e imitam as suas características. $\mathrm{O}$ sentimento de não estarem totalmente livres os leva em seguida a excessos. Assim nascem essas coisas 'dementes' que hoje em dia, estando em moda, são produzidas em massa. Em Darmstadt, quando da exposição de expressionistas, se teve que mostrar desenhos de crianças. Foram retirados no segundo dia porque mostravam de modo demasiadamente evidente o caráter fictício da ingenuidade dos artistas. Da mesma forma uma exposição de arte moderna não poderia suportar, sem algum dano, certos trabalhos de insanos ${ }^{16(31)}$.

Em 1922, o livro de Prinzhorn foi finalmente publicado. Tamanho foi o sucesso, que, em um ano, saiu a segunda edição. $O$ livro despertou a atenção não apenas de psiquiatras e psicólogos, mas igualmente de amantes da arte e do público intelectual em geral. A ideia dominante até então da 'esterilidade' da loucura foi contradita com as evidências apresentadas por Prinzhorn. As esculturas, as aquarelas e os desenhos dos chamados insanos chocavam o público da época. Havia muita coisa em comum entre Van Gogh, as obras do acervo da Clínica de Heidelberg, os já consagrados Kandisky e Klee, as telas cubistas de Picasso e de Braque, e os quadros de fauvistas como Matisse, sem falar de Cézanne, e assim por diante.

\section{A atualidade das 'intuições' de Prinzhorn}

Alguns dados biográficos são relevantes para se ter uma ideia da paixão de Prinzhorn pela arte. Antes de se interessar pela psiquiatria, Prinzhorn havia estudado a história da arte na Universidade Munique (1904 a 1908). Tão logo ganhou o título de doutor em filosofia, ele se entregou a executar um antigo projeto: fazer estudos de canto, se instalando em Leipzig com a sua esposa. Segundo Weber ${ }^{16}$, em sua tese de doutorado em filosofia, Prinzhorn visava à origem psicológica 
da atividade artística, a relação entre o jogo e o adorno, a natureza da ornamentação e da decoração, as características do simbólico, os princípios da 'colocação em forma' (Gestaltungsprinzipien). Em 1913, iniciou os seus estudos de medicina, motivado pelos transtornos mentais de sua esposa. Em 1917, ele passou no exame final na Faculdade de Medicina.

Deve-se tomar como ponto de partida para a abordagem do conteúdo do livro o próprio título da obra: 'Bildnerei der Geisteskranken'. Em inglês, foi traduzido como 'Artistry of the Mentaly Ill', o que em português seria

Arte (mestria) dos Doentes Mentais. Em francês, por sua vez, o título é 'Expressions de la Folie', com o subtítulo 'Dessins, peintures, sculptures d'asile' - em português, seria 'expressões da loucura, desenhos, pinturas, esculturas de asilo'. A referência que está sendo tomada neste artigo é a versão em francês ${ }^{17(53)}$.

Uma leitura atenta das traduções revela ambiguidades frente à riqueza do título original. Na introdução do seu livro, o próprio Prinzhorn explica a escolha do termo Bildnerei:

Nesses últimos tempos, o público tem ouvido falar mais de uma vez de 'arte dos loucos', de 'arte dos doentes mentais', de 'arte patológica' e de 'arte na loucura'. Nós não queremos, de forma alguma, empregar essas expressões. A acepção da palavra 'arte' e sua precisa carga afetiva comportam um julgamento de valor. Esse julgamento distingue certos objetos colocados em forma (Gestaltet), de outros completamente similares, que são absolutamente rejeitados como 'não-arte'. Estando dado que as obras (Bildner) que tratamos, assim como os problemas que elas nos levam a abordar, não são matéria para julgamento de valor, mas são visadas de um ponto de vista psicológico, nos parece pertinente reter o termo mais rico de sentido, ainda que pouco comum, que é 'Bildnerei', para um domínio quase que ainda desconhecido fora da psiquiatria. É designado por essa palavra tudo o que os doentes mentais produzem (Bilden), no sentido artístico do termo, em duas ou três dimensões ${ }^{\mathbf{1 7}(53)}$.

O termo alemão Bildnerei vem do verbo 'Bilden', que quer dizer formar; com derivações como 'Bild' (quadro), 'Bildnis' (retrato). Em nota de rodapé17, Prinzhorn lembra que o emprego de 'Bildnerei' denota, ao mesmo tempo, 'atividade e obra do criador'. Ao abrir mão do emprego da palavra 'arte', que de acordo com os seus critérios tinha uma conotação valorativa e pressupunha uma hierarquização, Prinzhorn revelou uma atitude inconformista e mesmo 'irreverente', desafiando os limites da ciência 'psiquiátrica-psicológica’ e da própria estética. Para designar a produção dos 'doentes mentais', ele preferiu utilizar, portanto, o termo alemão Bildnerei, 'expressão artística'.

O termo escolhido por Prinzhorn para trabalhar o processo formador foi precisamente 'Gestaltung'. Essa palavra alemã parece ser intraduzível para outro idioma. Pode-se apenas aproximar do sentido de 'Gestaltung': colocação em forma ('mise en forme', o preferido pelos tradutores franceses), configuração, estruturação, conformação, formatação, realização. Fazendo uso do termo 'Gestaltung', Prinzhorn buscou articular um conjunto de funções que ultrapassassem o indivíduo como tal, quer dizer, que fossem trans ou supraindividuais. Na medida em que todos os humanos têm esse impulso para 'colocar em forma', 'conformar'; assim como a própria natureza e o cosmos. Portanto, Prinzhorn queria um registro de pensamento bem distinto daquele da psicologia do 'indivíduo’ dominante na época. Um exemplo que ilustra bem os limites dessa psicologia foi o emprego usual da palavra 'expressão'. Existe o hábito de dizer que a obra é a expressão do artista - e são utilizados termos 
'psicológicos' como expressão do seu $\mathrm{Eu}$, de sua personalidade, de seu gênio, de seu inconsciente. Não haveria aí um reducionismo ao psicológico de algo que, por natureza, escapa a esses limites?

As obras organizadas por Prinzhorn foram submetidas a uma catalogação exaustiva, seguindo um enfoque formal e de conteúdo estético, incluindo a apresentação de dez 'pacientes-artistas', a partir da riqueza das suas obras. No começo da introdução ao livro, Prinzhorn afirmou:

O que foi publicado até hoje sobre tais obras de doentes mentais foi apenas destinado aos psiquiatras e abordando apenas um número restrito de casos iguais aos casos que qualquer psiquiatra encontra ao longo de sua carreira17(53).

Ali estava o ato inaugural de Prinzhorn, que o colocou em um lugar de destaque na história da relação arte-loucura. O desejo de Prinzhorn de tratar as obras examinadas como produtos artísticos levou-o a tomar a decisão de tratar os seus realizadores como indivíduos criadores, como artistas de fato, e, em uma série de estudos específicos de dez casos, dar-lhes nomes, embora se tratassem, ainda, de pseudônimos.

\section{A questão central}

Não é demais repetir que Prinzhorn pode ser considerado como um precursor do pensamento crítico em psiquiatria, na medida em que recusou radicalmente a atitude dos psiquiatras que consideravam as produções plásticas dos doentes como elementos sintomáticos suplementares úteis para o estabelecimento de um diagnóstico mais completo da doença. Ao contrário, a atitude propriamente estética parecia-lhe ser a mais adequada, por ser homogênea com o processo e o produto da criação artística. Por meio dessa atitude, não há como deixar de ser obrigado a ultrapassar as clivagens do normal e do anormal, do psicológico e do psicopatológico, do primitivo e do civilizado, da criança e do adulto; para não perder os laços dialéticos, como Prinzhorn alertava.

Observa-se uma dupla preocupação de Prinzhorn ao longo do seu livro: por um lado, criar condições para a suspensão do julgamento de valor e iniciar os profissionais do campo psíquico-psiquiátrico no desenvolvimento de uma atenção estética, terreno este no qual não há ciência que possa servir de guia seguro; por outro lado, inversamente, havia a preocupação em levar os especialistas da arte (historiadores, críticos e artistas) a suspenderem igualmente o seu próprio dogmatismo, que os levava a distinguir a priori o que é da arte e o que não é.

\section{O princípio da 'Gestaltung'}

O conceito de 'Gestaltung' é o básico, porque é o fundamento de toda atividade artística e a explicação da necessidade humana para a expressão. Nas palavras de Prinzhorn:

Nós concebemos a vida como uma hierarquia de processos de 'Gestaltung' e pensamos não poder chegar a esse ou a aquele julgamento, a não ser que nos apoiemos para tal sobre esse princípio. A pesquisa das raízes psicológicas da pulsão de 'Gestaltung' no homem nos faz descobrir na necessidade de expressão o centro das impulsões de 'Gestaltung' que alimentam todo o psiquismo. A partir desse centro se desenvolvem as diferentes tendências que, pela variedade de suas combinações, determinam o tipo de obra que se faz. Resta que, fundamentalmente, todo objeto a que se dá forma concretiza os movimentos expressivos de seu autor, perceptíveis imediatamente enquanto que tais, sem que intervenham uma finalidade ou qualquer outra tendência raciona|17(61)

Prinzhorn se propõe a buscar o sentido de todo o objeto formado na 'Gestaltung' 
enquanto tal, e o poder de perfeição da expressão da 'Gestaltung' em uma obra. As referências que ele emprega para entender a complexidade dos movimentos expressivos vão da biologia para a filosofia, da psicologia para a arte: Piderit, Darwin, Wundt, Croce e, sobretudo, Klages. Este último, Klages (18721956), filósofo e psicólogo alemão, foi para Prinzhorn quem havia ido mais longe com a teoria da expressão. Conforme a teoria de Klages, de acordo com Prinzhorn, os movimentos expressivos são os meios empregados pelo psíquico para se concretizar, seja por meio de uma descarga motora voluntária, como um gesto provocado pela ira ou pela alegria, passando por fenômenos do sistema vegetativo, como o enrubescimento da face do rosto, ao 'gesto sonoro' da palavra e a sua concretização na escrita e na obra plástica. Enquanto Klages orientou a sua pesquisa para a grafologia, Prinzhorn estendeu as suas intuições para a realização dos movimentos expressivos em obras de arte. Para Prinzhorn, quanto mais um fenômeno expressivo está enraizado subjetivamente, mais o ser humano é incapaz de conhecê-lo quantitativamente ou conceitualmente. Através de suas próprias palavras, é possível compreender qual o seu pensamento a respeito:

Temos que ser loucos para sermos persuadidos que se possa definir o que faz o som de um violinista através de medidas de vibrações e de timbres, ou mesmo que o que há de expressivo no jogo de luzes de um Rembrandt por verificações em uma escala das cores ${ }^{17(67)}$.

Por conseguinte, Prinzhorn entende ser necessário distinguir e opor a esfera dos fatos mensuráveis ao campo dos fatos de expressão aonde o psíquico aparece imediatamente e é percebido sem a mediação de um aparelho intelectual. Neste sentido, sua tese vai ainda mais longe:

Os movimentos expressivos não são submetidos, enquanto que tais, em sua essência, a qualquer outra finalidade que não seja aquela de concretização do psíquico, e desse modo de estabelecer a comunicação com o outro ${ }^{17(67)}$.

Portanto, é universal 'o impulso à expressão'. Este impulso não é meramente autoexpressivo, mas tem como meta estabelecer contato, 'comunicar-se com o outro'.

Inerentes a esse impulso de expressão para se comunicar com o outro e com o mundo, Prinzhorn identificou seis impulsos significativos menos importantes. Ele falou do 'impulso para atividade'. O movimento é a principal manifestação desse impulso. É a atividade lúdica humana, gratuita, sem finalidades instrumentais. Vai desde certos tipos de invenção de formas, como rabiscos feitos para se distrair durante uma conferência ou em reuniões, até os desenhos rupestres de povos primitivos ou os jogos livres com formas e cores feitos em uma tela. Ou os jogos infantis, para dar mais um entre tantos exemplos. Há uma relação íntima entre o jogo e a criatividade.

Um outro impulso postulado por Prinzhorn é o da 'ornamentação', que ele definiu como uma tendência ao enriquecimento do corpo, dos objetos, e do meio ambiente pela adição de elementos perceptivos.

O homem, ao invés de se encerrar passivamente em seu meio, ele experimenta a necessidade de imprimir nele a marca de sua existência para além do campo da atividade útil. Essa necessidade toca tudo que as necessidades da vida cotidiana suscitaram, como habitação, vestuário, armas, ferramentas, utensílios que nasceram progressivamente, desde a cerâmica dos primitivos e seus instrumentos de osso e de pedras, até o cinzeiro, a lâmpada e o livro de hoje em dia'17(78).

Ainda outro impulso derivado da necessidade de expressão é a 'tendência a ordenar', que é caracterizada por uma motivação para impor ordem nas formas aleatórias ou caóticas, ou a 
experiência para o uso de padrões regulares, simétricos, proporcionais e rítmicos. Sabe-se que o uso de meios artísticos de expressão é, muitas vezes, empregado para dar ordem às experiências de mudanças caoticamente ocorridas no mundo-de-vida do ser humano.

Se nós considerarmos a estrutura dos cristais e das plantas, a alternância do dia e da noite, do fluxo e do refluxo, do verão e do inverno, nós estaremos muito inclinados a renunciar ao antropomorfismo para ver antes a medida e o modelo dos princípios de 'Gestaltung' no desenrolar rítmico de todos os processos vitais. Entretanto, nos importa ainda mais constatar que essas tendências de ordenamento entram necessariamente e com mais certeza em jogo quando a parte da tendência a reproduzir é diminuída17(79).

O quinto impulso postulado por Prinzhorn é o 'impulso de imitação'. Ao discutir esse impulso - 'a tendência a imitar ou copiar' -, ele sublinhou que certos períodos históricos da arte foram dominados pela preocupação com a verossimilitude, havendo aí um inegável prazer. Não obstante, Prinzhorn fez questão de deixar claro que esse simples impulso tem sido superestimando na teoria da arte, em prejuízo dos outros. Com isso, Prinzhorn estava se referindo à representação e ao realismo na arte, tomando partido das vanguardas desde o Impressionismo.

A doutrina da imitação em arte é um dos exemplos mais chocantes da fascinação tenaz que ideias sustentadas por um dogma podem exercer durante séculos sobre a humanidade, mesmo se manifestamente elas são falsas ${ }^{17(82)}$.

Finalmente o sexto impulso, a 'necessidade de símbolos'. O que significa:

Em termos psicológicos, trata-se da tendência a evocar, na 'Gestaltung', sensíveis conjuntos de sentimentos e de representações, que, por natureza, não podem por si serem visualmente apresentados. $\mathrm{O}$ espectador não pode, portanto, simplesmente perceber o motivo, como no caso de uma reprodução ou de um ornamento ${ }^{17(86)}$.

Havendo apresentado os fundamentos da sua teoria, Prinzhorn dedicou a maior parte do seu livro à apresentação detalhada de dez artistas, entre as centenas daqueles da coleção de Heidelberg. Descrever aqui no artigo cada um desses dez casos 'estéticos', sem a apresentação visual das suas obras, seria um esforço inócuo, pois se perderia a própria essência estética desses trabalhos. São obras que na época tiveram um fortíssimo impacto entre os artistas, psiquiatras e psicanalistas, e o público em geral. Quase ao final do seu livro, a respeito das reações do público às obras expostas, Prinzhorn fez a seguinte análise:

No que diz respeito com a afinidade com a arte moderna, nós pudemos observar uma série de reações que lançaram luz sobre o papel que exercem em todos os julgamentos elementos afetivos ou centros de interesse pessoais. Com efeito, as pessoas conservadoras sobre o plano cultural ou com as costas voltadas para a história, ou não eram em absoluta sensíveis à originalidade dessas obras, ou ensaiaram interpretar imediatamente uma impressão rápida em termos de tendências culturais e políticas. Entretanto, todos os visitantes profundamente preocupados pelos problemas da criação artística, ou simplesmente pela psicologia do que está fora da norma, se interessaram com uma extraordinária intensidade muito particularmente com as obras mais estranhas. Entre aqueles que eram artistas, alguns, tanto as pessoas moderadas quanto os expressionistas convencidos se absorveram no estudo das singularidades dessas obras, admiraram sem reservas um grande número de peças e rejeitaram outras, sem imaginar de maneira alguma uma distinção entre o sano e o doente17(364-365). 
A reação conservadora sempre esteve presente, é indispensável ser reconhecido. Um exemplo bastante eloquente, que ficou marcado indelevelmente na história da primeira metade do século XX a subida de Hitler ao poder deu início a uma ofensiva, visando arruinar a arte moderna e artistas, na base das teorias que aproximaram arte e doença mental.

No entendimento de MacGregor:

começando em 1933, uma série de eventos cuidadosamente organizados sinalizaram o fim da liberdade artística no Terceiro Reich. O Bauhauss [...] foi fechado; diretores de museus e professores de arte passaram a ser demitidos; e exibições de arte moderna foram fechadas e o trabalho confiscado 10(240).

Sabe-se que o nazismo buscou de todas as formas adequar as teorias científicas às suas doutrinas de superioridade racial. A ideia de uma arte patológica serviu perfeitamente ao propósito de reconhecer todos aqueles que não correspondiam aos critérios de 'raça pura'.

Em julho de 1937, diz MacGregor, a captura de trabalhos da 'arte degenerada' começou em torno de 16 mil trabalhos de arte foram removidos das coleções públicas, todas identificadas como degeneradas. Isso incluiu quase todos os trabalhos dos pintores expressionistas pertencentes aos museus alemães. Cerca de 400 mil quadros foram incinerados em 1939; e o restante foi vendido fora do país. Além de terem seus trabalhos vilipendiados e destruídos, os supostamente artistas degenerados foram molestados e perseguidos ${ }^{10}$.

$\mathrm{O}$ auge do ataque nazista à arte contemporânea da época ocorreu com uma exposição minuciosamente preparada: 'Entartete Kunst' ('Arte Degenerada'), aberta em julho de 1937, em Munique. Seu objetivo: denegrir as novas tendências e injuriar os artistas, fazendo prevalecer uma visão Nacional Socialista da arte. Segundo uma citação feita por MacGregor, Hitler assim se referiu à exposição: "Uma lição útil ilustrando as profundezas do declínio dentro do qual o povo (alemão) caiu"10(241-242). Manipulando os sentimentos do povo alemão, cuja tendência entre muitos era justamente a de rejeitar a arte contemporânea, a exposição colocou lado a lado algumas das obras representadas na coleção de Heidelberg e obras de artistas como Kandinsky, Nolde, Klee, Krchner, Kokoschka e Chagall. As obras da coleção de Heidelberg foram disponibilizadas pelo novo diretor da clínica, Calr Scheider, responsável pelo programa de extermínio dos doentes mentais na Alemanha, que substituiu o demitido Dr. Wilmanns. As obras dos artistas da vanguarda da arte da época estavam na 'Entartete Kunst' porque haviam sido confiscadas por Ziegler.

Por que associar 'arte moderna' com 'arte degenerada'? Hitler viu a arte moderna como perigosa, observa MacGregor, porque causava risco à saúde mental do povo alemão. Ela representava um assalto à razão, à verdade, e ao pensamento claro. A arte moderna era perigosa não porque mentia, mas porque ela forçava qualquer um a se confrontar com aspectos do self que eram obscuros, difíceis e profundamente irracionais ${ }^{10}$.

\section{A atualidade da obra de Prinzhorn no Brasil}

O que se denomina como autonomia do 'campo artístico-cultural' frente ao 'campo psiquiátrico', antecipada e defendida de forma brilhante e pioneira por Prinzhorn, ainda é uma demanda contemporânea. De imediato, porque através das expressões 'artístico-culturais' aqueles diagnosticados como doentes mentais pela psiquiatria muito em particular com a suposta 'esquizofrenia' ou outras psicoses - frequentemente encontram meios para se expressar frente aos parâmetros dominantes da razão ${ }^{\mathbf{1 8}}$. Quando conseguem ver seus quadros em uma exposição, suas poesias sendo publicadas, seu samba-enredo sendo cantado pelo 
bloco carnavalesco formado por 'usuários' dos serviços, técnicos e a população em geral; quando suas composições musicais são gravadas em um $\mathrm{CD}$ e vendidas, quando são atores em uma companhia teatral, quando participam de shows musicais lado a lado com artistas já consagrados na Música Popular Brasileira, e assim por diante ${ }^{3}$.

Aquelas pessoas que, durante séculos, por terem um diagnóstico de esquizofrenia ou qualquer outro diagnóstico de transtorno mental, tinham como destino a vida em um manicômio, nos tempos atuais, no Brasil, uma parcela significativa está vivendo em suas casas ou em casas assistidas, sendo tratada em Centros de Atenção Psicossocial (Caps), trabalhando em cooperativas sociais, atuando em coletivos de arte-cultura, e com muitas outras possibilidades. Vivem com relativa liberdade e mais autonomia do que antes, $\mathbf{6 , 9 , 2 0 , 2 1 , 2 2 . ~}$

Prinzhorn não poderia ter deixado de exercer influências sobre alguns pioneiros brasileiros no modo de se relacionar com a chamada arte dos loucos. Dois deles merecem ser destacados: Osório César (1895-1979) e Nise da Silveira (1905-1999), já mencionados no começo deste artigo. Osório César foi médico no Hospital Psiquiátrico Juqueri, em Franco da Rocha (SP). Nise da Silveira foi médica no Hospital Psiquiátrico Pedro II, no Rio de Janeiro (RJ). A exemplo de Prinzhorn, os dois criaram novas relações entre a arte e a loucura. As obras nascem em meio hospitalar e são posteriormente levadas para o contexto artístico, suscitando debates em ambos os domínios. O acervo organizado por Osório César tem o nome de Museu Osório César. E aquele organizado por Nise da Silveira, em 1952, é mundialmente conhecido por Museu de Imagens do Inconsciente, no interior de uma instituição que hoje leva o seu nome, Instituto Municipal Nise da Silveira.

Há diferenças importantes entre Prinzhorn, Osório César e Nise da Silveira que merecem ser destacadas. A primeira diferença é que, diferentemente de Prinzhorn, mergulhado na tarefa de desenvolver uma teoria estética das obras dos esquizofrênicos, tanto Osório César quanto Nise da Silveira buscaram subordinar a riqueza plástica das obras às suas teses psicológicas. Nesse sentido, os dois não deixam de reproduzir o que sempre a psiquiatria procura fazer com as obras de seus pacientes: ilustrar como exemplos as suas teses para as origens ou o significado das perturbações psíquicas. Osório César e Nise da Silveira reconhecem a mesma origem à arte sã e à arte dos alienados: o inconsciente. $\mathrm{O}$ 'inconsciente' de Osório César era freudiano. $\mathrm{E}$ o de Nise da Silveira era o 'inconsciente coletivo', de Jung. Osório César pretendia descodificar, através da representação simbólica dos doentes, acontecimentos da infância ou complexos amorosos na origem do distúrbio psíquico. Os seus critérios de análise têm como referência fundamental o livro de Freud 'A interpretação dos sonhos'. A respeito, é eloquente esse trecho da sua obra:

\section{Assim, os órgãos genitais masculinos são, por exemplo, representados por bengalas, limas, serpentes, punhais, revólveres, torneiras [...] os órgãos femininos têm sua representação em va- sos, caixas, cofres, portas, frutos etc.8(27).}

Por sua vez, a Nise da Silveira procurava aceder às imagens expressas interpretando supostos conteúdos internos universalizáveis, como os mitos ou os contos. Seguindo a perspectiva de Jung, Nise constatava que graças às perturbações psíquicas se tornava possível acessar ao inconsciente coletivo, sendo permitido assim reconhecer inúmeras imagens arquetípicas nas criações artísticas dos pacientes psiquiátricos. Por exemplo, o self, simbolizado pelo arquetípico da mandala "é o princípio e arquétipo da orientação e do sentido, nisso reside a sua função curativa"9(52-53).

A outra diferença é que, enquanto Prinzhorn não exercia a clínica psiquiátrica propriamente dita, Osório César e Nise da Silveira tinham essa preocupação; a arte sendo um meio terapêutico - arte-terapia. As consequências dessas diferenças: por um lado, a ruptura radical com a psiquiatria, tal 
como proposta por Prinzhorn; por outro, a inovação no campo psiquiátrico, embora mantendo-se na mesma ordem simbólica, ou seja, na ordem simbólica da própria psiquiatria, como parece ter sido o caso de Osório César e Nise da Silveira.

É notória a importância de Osório César, assim como a de Nise da Silveira, para o diálogo entre a psiquiatria e o campo da arte no Brasil. Osório César integrou, pela primeira vez, em contexto museológico, as produções dos doentes mentais internados. Para se ter uma ideia do seu papel, em 1942, ele foi responsável pela curadoria do Salão de Arte dos Loucos, parte integrante da Segunda Semana de Arte Moderna. Em 1948, ele organizou uma exposição das obras dos pacientes de Juqueri no Museu de Arte de São Paulo (Masp). E não menos notória é a importância de Nise da Silveira e do Museu de Imagens do Inconsciente por ela fundado no Centro Psiquiátrico Pedro II. A coleção desde então desperta o interesse de um grande público.

\section{Considerações finais}

Embora pouco conhecida, a perspectiva inaugurada por Prinzhorn é até hoje atual. Desde a coleção organizada por ele na Clínica de Heidelberg, exposta a partir de critérios estéticos, a relação entre arte e loucura é desafiadora - seja para o campo artístico propriamente dito, seja para o campo psiquiátrico. O livro escrito por Prinzhorn, com as suas hipóteses teóricas para explicar o fenômeno da criação, universalmente presente entre os seres humanos, apresenta ao longo das suas páginas desafios enormes para os tempos atuais. A inovação e os desafios que Prinzhorn legou têm sido referência, desde então, tanto para o campo artístico-cultural como para o campo psiquiátrico. As experiências, no Brasil, de Osório César e Nise da Silveira são exemplares. Com a reforma psiquiátrica em processo no País há pelo menos três décadas, condições concretas e institucionais para o reconhecimento da autonomia do campo artístico-cultural com relação ao campo psiquiátrico têm sido criadas. Ao trazer para o conhecimento do público brasileiro a obra de Hans Prinzhorn, o artigo pretende contribuir para o aprofundamento e a radicalização da dimensão cultural do processo da reforma psiquiátrica. 


\section{Referências}

1. Pinel P. Tratado Médico-Filosófico sobre a Alienação ou Mania. Porto Alegre: UFRGS; 2007.

2. Amarante P. Saúde mental e atenção psicossocial. 4. ed. Rio de Janeiro: Fiocruz; 2015.

3. Amarante P, Freitas F, Panda M, et al. El campo artístico-cultural en la reforma psiquiátrica brasileña: el paradigma identitário del reconocimiento. Rev. Sal. Colectiva. 2013 set-dez; 9(3):287-299.

4. Milhomens AE, Lima EMFA. Recepção estética de apresentações teatrais com atores com história de sofrimento psíquico. Interface. 2014; 18(49):377-88.

5. Fonseca TMG, Tomazoni AR, Lockmann V, et al. Espaços heterotópicos, imagens sobrepostas: Encontros entre arte, loucura e memória. Rev. Psic. Ciênc. e Profissão. 2009; 29(2):406-415.

6. Fraize-Pereira, JA. O desvio do olhar: dos asilos aos museus de arte. Rev. Psicol. USP. 1999; 10(2):47-58.

7. Lima EMFA, Pelbart TPP. Arte, Clínica e Loucura, territórios em mutação. Rev. Hist. Ciênc. Saúde. 2007 jul-set; 14(3):709-735.

8. Figueira E. Psicologia da Arte. São Paulo: Edição do Autor; 2003.

9. Silveira N. Imagens do Inconsciente. Brasília, DF: Alhambra;1981.

10. MacGregor JM. The Discovery of the Art of the Insane. New Jersey: Princeton University Press; 1989.

11. Zolberg V, Cherbo JM. Outsider Art: Contesting Boundarie in Contemporary Culture. Cambridge: Cambridge University Press; 1997.
12. Freud S. A interpretação dos sonhos. Rio de Janeiro: Imago; 2009.

13. Freud S. Leonardo da Vinci e uma lembrança de sua infância. Rio de Janeiro: Imago; 2009.

14. Freud S. O Moisés de Michelangelo. Rio de Janeiro: Imago; 2009.

15. Breton A. Le Surréalisme et la peinture. Paris: Gallimard; 1965.

16. Weber M. Apresentação da tradução. In: Prinzhorn A. Expressions de la Folie, dessins, peintures, sculptures d'asile. Paris: Gallimard; 1984.

17. Prinzhorn H. Expressions de la Folie, dessins, peintures, sculptures d'asile. Paris: Gallimard; 1984.

18. Providello G, Yasauí AS. Loucura em Foucault: arte e loucura, loucura e desrazão. Hist. Ciênc. Saúde - Manguinhos. 2013; 20(4):1515-1529.

19. Lima EMFA. Machado de Assis e a psiquiatria: um capítulo das relações entre arte e clínica no Brasil. Hist. Ciênc. Saúde - Manguinhos. 2009; 16(3):641-654.

20. Liberato MTC, Dimenstein M. Arte, loucura e cidade: a invenção de novos possíveis. Psicol. Soc., 2013; 25(2):272-281.

21. Lima EMFA. A Exposição IN PACTO e o viver junto: criação e convivência. In: Castro ED, organizador. Programa Permanentes Composições Artísticas e Terapia Ocupacional - PACTO. São Paulo: Catálogo Virtual Ilustrado; 2007.

22. Castro ED, Lima EMFA. Resistência, inovação e clínica no pensar e no agir de Nise da Silveira. Interface, Educ. maio-ago 2007; 11(22):365-76. 
23. Breton A. Manifesto of Surrealism. Michigan: Ann Arbor; 1972.

24. Chipp HB. Teorias da Arte Moderna. São Paulo: Martins Fontes; 1999.

25. Nise da Silveira: imagens do inconsciente en- tre psicologia, arte e política. Est. Av. 2003; 17(49):197-208.

Recebido em 22/08/ 2017

Aprovado em 02/04/2018

Conflito de interesses: inexistente

Suporte financeiro: não houve 